\title{
Optogenetic Approaches to Target Specific Neural Circuits in Post-stroke Recovery
}

\author{
Michelle Y. Cheng ${ }^{1}$ • Markus Aswendt ${ }^{1}$ - Gary K. Steinberg ${ }^{1}$
}

Published online: 23 December 2015

(C) The American Society for Experimental NeuroTherapeutics, Inc. 2015

\begin{abstract}
Stroke is a leading cause of death and disability in the USA, yet treatment options are very limited. Functional recovery can occur after stroke and is attributed, in part, to rewiring of neural connections in areas adjacent to or remotely connected to the infarct. A better understanding of neural circuit rewiring is thus an important step toward developing future therapeutic strategies for stroke recovery. Because stroke disrupts functional connections in peri-infarct and remotely connected regions, it is important to investigate brain-wide network dynamics during post-stroke recovery. Optogenetics is a revolutionary neuroscience tool that uses bioengineered lightsensitive proteins to selectively activate or inhibit specific cell types and neural circuits within milliseconds, allowing greater specificity and temporal precision for dissecting neural circuit mechanisms in diseases. In this review, we discuss the current view of post-stroke remapping and recovery, including recent studies that use optogenetics to investigate neural circuit remapping after stroke, as well as optogenetic stimulation to enhance stroke recovery. Multimodal approaches employing optogenetics in conjunction with other readouts (e.g., in vivo neuroimaging techniques, behavior assays, and next-generation sequencing) will advance our understanding of neural circuit reorganization during post-stroke recovery, as well as provide important insights into which brain circuits to target when designing brain stimulation strategies for future clinical studies.
\end{abstract}

Michelle Y. Cheng

mycheng@stanford.edu

Gary K. Steinberg

gsteinberg@stanford.edu

1 Department of Neurosurgery, R281, Stanford University School of Medicine, 300 Pasteur Drive, Stanford, CA 94305-5327, USA
Keywords Stroke $\cdot$ Recovery $\cdot$ Optogenetics $\cdot$ Neural circuit . Remapping $\cdot$ Brain stimulation

\section{Introduction to Stroke Recovery}

Approximately 800,000 strokes occur each year in the USA and most stroke survivors suffer long-term deficits. The only proven therapies for ischemic stroke are intravenous tissue plasminogen activator (tPA) and intra-arterial thrombectomy, both of which must be administered within $6 \mathrm{~h}$ of stroke onset, a scenario that is applicable to very few patients [1-4]. Increasing attention has therefore focused on understanding how the surviving brain gains new function, and developing potential therapies that promote long-term post-stroke recovery.

\section{Functional Recovery After Stroke}

Functional recovery after stroke has been observed in both human and animal studies [5-7]. After injury, the brain undergoes reorganization and rewiring and this can occur in areas adjacent or remotely connected to the infarct [8-10]. Significant turnover of dendritic spines and axonal sprouting in the peri-infarct zone after stroke is correlated with improved functional outcome [7, 8, 11, 12]. Cortical remapping during stroke recovery is accompanied by the development of prolonged sensory responses and new structural circuits in the peri-infarct and connected cortical areas, such as premotor, motor, and somatosensory cortex $[8,13,14]$. Sprouting of axons is an activity-dependent process [15], and increasing neuronal activity can result in release of neurotrophins, such as nerve growth factor and brain-derived neurotrophic factor, which have been shown to improve recovery by enhancing 
axonal sprouting and dendritic branching [16-18]. An axonal sprouting transcriptome after stroke has been reported, with a molecular growth program that regulates the axonal sprouting processes [19]. This axonal growth transcriptome can potentially reveal important candidates that mediate repair and recovery after stroke. Some of these candidates have recently been demonstrated as important regulators of post-stroke axonal sprouting, including ephrin-A5, which inhibits axonal sprouting [20], and growth and differentiation factor 10, which promotes axonal sprouting [21].

As stroke can disrupt functional connections and cause brain-wide network changes [22], it is important to understand the spatial and temporal progression of neural circuit dynamics and to identify which neural circuits are beneficial for stroke recovery. Brain imaging studies in stroke patients have yielded important insights about functional cortical remapping [23-25]. In stroke patients with good recovery, there is often a transient bilateral activation that occurs in both cortical hemispheres while moving the affected limb, suggesting the involvement of contralesional cortical activation in stroke recovery [23-25]. Data from our laboratory and that of others have shown that increasing the excitability of the ipsilesional motor cortex (iM1) after stroke is beneficial for recovery [5, 23, 26, 27]. However, it is less clear whether activation of other areas such as the contralesional cortex is beneficial or maladaptive, or not involved [28]. Furthermore, most cortical remapping studies have relied on peripheral stimulations such as limb movement, which is limited to sensory and/or motor cortex activation, and have neglected subcortical and other remotely connected brain regions. Stroke can cause a transient reduction of cerebral blood flow (CBF), and depression of neuronal metabolism in remotely connected brain regions, a phenomenon known as diaschisis [29]. For example, a common form of diaschisis observed in stroke patients is crossed cerebellar diaschisis where stroke causes a depression of brain function in the cerebellum [30]. It has been reported that crossed cerebellar diaschisis may be a good prognostic indicator for stroke recovery [30, 31]. As stroke can cause changes in peri-infarct and connected remote regions, it is important to investigate brain-wide network dynamics during post-stroke recovery, and to determine which of these changes are beneficial for recovery.

\section{Current Brain Stimulation Techniques Used to Study Stroke Recovery}

Clinical and research efforts have focused on promoting plasticity and recovery after stroke. Various strategies have been shown to enhance recovery in preclinical models and patients, including pharmacological treatment, rehabilitation (e.g., constraint-induced therapy) [32-34], stem cell transplantation $[35,36]$, and brain stimulation [37-43]. In particular, brain stimulation is a promising area of research because it allows direct activation and manipulation of the target area's excitability. A number of studies have used invasive and noninvasive brain stimulation techniques to study recovery after stroke [37-43]. These include cortical microelectrode stimulation, deep brain stimulation, transcranial magnetic stimulation (TMS), and transcranial direct current stimulation (tDCS). As discussed in the previous section, post-stroke recovery involves changes in perilesional reorganization, recruitment of ipsilesional and contralesional areas, and changes in interhemispheric inhibition. Studies suggest that an initial transient activation in both hemispheres positively correlates with recovery [44-46], while further prolonged activation of the contralesional cortex can worsen recovery $[9,47]$. The interhemispheric competition model, which supports this potential for contralesional activation to adversely affect stroke recovery (Fig. 1) [48, 49], states that in a normal nonstroke brain each cortical hemisphere maintains independent processing, and each inhibits the other through transcallosal fibers $[49,50]$. However, stroke disrupts this interhemispheric balance when the ipsilesional cortex fails to maintain its inhibition on the contralesional cortex. This results in an excessive inhibition from the contralesional cortex to the ipsilesional cortex through the transcallosal fibers, which further reduces motor output of the affected limb and results in worsened recovery [49-51].

Invasive brain stimulations, such as cortical electrical stimulations in the ipsilesional M1, have demonstrated improved motor function and increased dendritic plasticity after stroke $[39,52,53]$. The combination of electrical cortical stimulation with rehabilitative training can further enhance motor recovery, improve structural plasticity, and is more efficacious than rehabilitation alone [54-56]. Cortical microstimulations were promising in preclinical studies, and clinical trials were successful in phases I and II. However, phase III trials did not indicate an advantage with the combined cortical electrical stimulation and rehabilitation approach [38, 57, 58]. Some improvements that could be made in future cortical stimulation trials
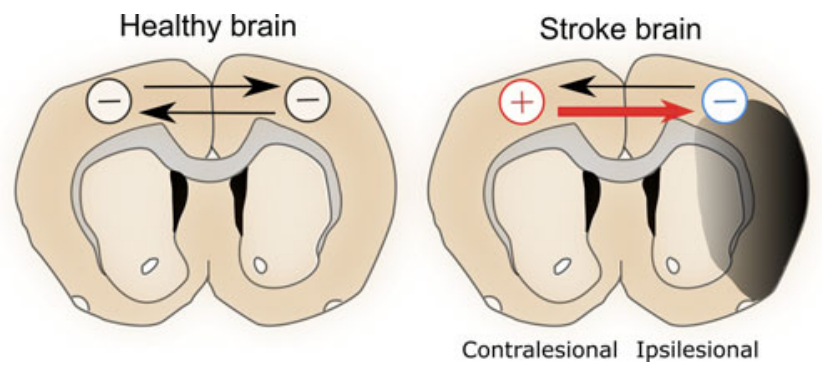

Fig. 1 The interhemispheric competition model states that homotopic areas in the healthy brain inhibit each other. When stroke occurs this interhemispheric inhibition is disrupted, leading to a strong inhibition to the ipsilesional hemisphere. The result is a disinhibited and thus excessively activated contralesional cortex, which can further reduce motor output of the affected limb and worsen recovery 
include ways to better localize the site of stimulation and patterns of reorganization to the target site, and more patient-specific and severity stage-specific stimulations. Deep brain stimulations targeting the thalamus (Th) and periaqueductal gray matter for post-stroke movements and neuropathic pain have demonstrated efficacy in human studies [59-61]. Deep brain stimulations in the cerebellar dentate nucleus in rats have also been shown to promote post-stroke recovery and enhance synaptic plasticity and reorganization in the perilesional cortex [62-65].

Noninvasive stimulations such as tDCS and repetitive TMS have also demonstrated promising results in promoting poststroke recovery in both animal and human studies [66, 67]. TMS and tDCS have also been widely used to investigate the role of the contralesional cortex, although stimulations in the contralesional cortex have shown inconclusive results [23, 41, $45,68]$. This could be due to the timing of manipulation and severity of stroke. Nevertheless, these brain stimulation techniques have been shown to promote recovery when stimulating the ipsilesional cortex and their noninvasive application is a major advantage, as cortical excitability can be modulated in a painless procedure $[43,69,70]$. However, these techniques are limited by imprecise and indiscriminate activation or inhibition of all cell types near the stimulated site, thus they can stimulate multiple cell types, such as neurons, astrocytes, and oligodendrocytes, which have all been shown to affect remodeling and recovery [71-75]. Furthermore, specific excitatory or inhibitory circuit modulations are nearly impossible with these techniques.

In contrast, optogenetics circumvents these issues because it can activate or inhibit specific cell types and circuits with millisecond temporal precision [76, 77]. This cell type specificity allows manipulation of specific circuits and thus more targeted manipulations, which should help pinpoint the circuits and molecular mechanisms that underlie diseases. Optogenetic approaches have been used in rodents to probe neural circuits for several neurological/neurodegenerative diseases, including Parkinson's disease [78, 79], epilepsy [80, $81]$, and stroke $[26,82]$. In the next sections we will first introduce optogenetics and its developments, and then review the current understanding of remapping and recovery after stroke from recent studies using peripheral and optogenetic stimulation, as well as the use of optogenetic stimulation to enhance post-stroke recovery.

\section{Introduction to Optogenetics}

\section{The Optogenetics Toolbox and Developments}

Optogenetics encompasses a novel set of light-gated ion channels, which revolutionized the bottom-up strategy for linking neuronal action potentials of cell populations to neuronal circuits controlling behavior. The blue light-sensitive channelrhodopsin (ChR2) from Chlamydomonas reinhardtii was the first microbial opsin to be genetically inserted into neurons and used for sustained control of millisecondprecision action potentials [83]. The 7 transmembrane protein ChR2 incorporates a covalently all-trans retinal that absorbs a blue photon $(470 \mathrm{~nm})$ and changes its conformation to the 13-cis-retinal, which induces the $6^{\circ} \mathrm{A}$ pore to open. The pore is closed within milliseconds as the retinal relaxes back to the all-trans form [84]. Upon stimulation with blue light, ChR2 opens and allows cations to flow into the cell, causing depolarization and neuronal firing. Halorhodopsin (NpHR), the main rhodopsin for neuronal inhibition, was discovered from the halophilic bacterium Natronobacterium pharaonis [85]. Unlike ChR2, NpHR is a chloride pump activated by yellow light $(580 \mathrm{~nm})$ and transports 1 chloride ion into the cell per photon, and thus requires constant light for continuous inhibition. Owing to the spectral separation between NpHR and ChR2, these two opsins allow optical inhibition and activation in 1 experiment [86].

Extensive screening for new microbial opsins, mutagenesis, and human codon optimization has led to a variety of optogenetic tools for fast excitation, inhibition, and switch on/off at different wavelengths [76, 87]. One of the most widely used ChR2 is a humanized variant (ChR2-H134R) in which algal codons were substituted with mammalian codons and a single point mutation was inserted at position $\mathrm{H} 134$, in order to achieve higher expression levels and generate larger photocurrents than the wild-type ChR [88]. The optogenetic toolbox is rapidly expanding, including development of ultrafast and more consistent neuronal spiking tools like ChETA [89], and yellow/red-shifted ChR variants such as VChR1 (545 nm), ReaChR (590-630 nm), and Chrimson (625 nm) [90-92]. Higher wavelengths penetrate better into brain tissue because of less absorption and scattering, which allows targeting of deep brain structures and even transcranial optical activation of neurons [90]. Similar improvements have been made with optogenetic tools for inhibition. A red lightdrivable version of $\mathrm{NpHR}$, Jaws, was recently developed [93]. In addition, a 200-fold more light-sensitive chlorideconducting $\mathrm{ChR}$ (iC1C2) was developed that allows neuronal inhibition with blue light [94]. Besides being more sensitive to light, iC1C2 opens for a longer time, up to a minute after stimulation, and can be deactivated by red light. This is more advantageous as increased light sensitivity and longer channel opening allow less laser exposure, thus reducing heat damage to tissues. Similarly, a more superior neuronal silencing tool than NpHR has been discovered. These higher light-sensitive proton pumps (Arch and ArchT) were discovered from arachaebacteria and allow more efficient neuronal silencing with less light exposure [95].

Step-function opsin (SFO) is another family of ChR but exhibits prolonged activation, even after the light is off, and can be deactivated by yellow light [96]. The newer stabilized 
step function opsin (SSFO) has an inactivation time constant of approximately $30 \mathrm{~min}$ [97], and is thus particularly suitable for stimulation paradigms that require prolonged activation without continuous exposure to the laser. This is advantageous as continuous laser pulses at high power can cause heat damage to tissues. Furthermore, there are an array of developments in optical control of signaling pathways, including Opto-XRs, which allow $\mathrm{G}$ protein-coupled receptor-mediated signaling (Gq, Gs, or Gi/o-coupled), light-gated enzyme activation, and light-sensitive protein-protein interactions [98, 99]. These optogenetic tools are very useful for manipulating specific cell types and circuits when probing the neural circuit mechanisms that underlie diseases.

In addition to controlling neuronal firing in specific cells and brain regions, the study of neural circuits requires methods that simultaneously monitor the activity of the neuronal population. The activity of larger neuronal populations and circuits activated during complex behavior can be concurrently recorded on a global scale by techniques such as electroencephalography (EEG), magnetoencephelography, optical intrinsic imaging [100], and cortical voltage-sensitive dye (VSD), whereas for more localized neuronal populations (smaller population of neurons) such as local deep layer microelectrode arrays [101] and calcium imaging [102], the brain area must be selected beforehand.

More recently, optogenetic tools have overcome the limitation of poorly defined cell population recordings by enabling cell type-specific optical recordings of large numbers of neurons' action potentials at both single-cell and ensemble levels [103]. Cell identity can be achieved by targeting genetically encoded calcium or voltage indicators. Calcium indicators respond to an increase in intracellular $\mathrm{Ca}^{2+}$ concentration and emit fluorescence. The current best-performing calcium indicator is GCamP6, which has increased optical performance toward single spike detection sensitivity in many neuron types [104]. In addition, voltage-sensitive fluorescent proteins, an engineered voltage-sensing domain fused with a fluorescent protein, track voltage changes more directly but at the expense of sensitivity [103]. Genetically encoded voltage indicators enable optical imaging of action potentials in vivo [105]. Fast in vivo imaging is achieved by 2-photon microscopy through a cranial window preparation down to layer $2 / 3$ neurons in anesthetized [106] and awake head-restrained mice [107], or through a miniaturized integrated microscope for imaging deeper structures [108]. Implantation of a special optical fiber photometry setup provides access to local GCamP signals from deep brain nuclei [109]. The single fiber optic invented for fiber photometry provides chronic and stable access to deep brain structures by recording GCamp fluorescence emission in freely moving mice. Gunaydin et al. [109] have used this technique to record neural activity during social behavior in genetically and connectivity-defined projections between ventral tegmental area-to-nucleus accumbens. Such in vivo deep brain recording of neural activity could be important to study the role of thalamocortical and cerebellothalamic projections during stroke recovery. Notably, both optogenetic toolsets - stimulation and recording of neural circuit activity - have been combined in an all-optical setting for photostimulation and fast calcium imaging without spectral overlap in vivo $[110,111]$.

\section{Benefits of Optogenetics}

The key advantage of optogenetics over conventional microelectrode stimulation/recording is its ability to control celland circuit-specific activation and/or inhibition with temporal precision. Given the complex network and numerous distinct subtypes of excitatory and inhibitory neurons, cells during electrical stimulation may cause cancellation effects between circuits, making it difficult to characterize detailed local circuits and long-range projections. A recent study compared optogenetic and electrical stimulation of dopamine release in the terminals [112], and demonstrated that selective optogenetic stimulation produced higher dopamine release than electrical stimulation. The same study found that local electrical stimulation produced multisynaptic modulation on dopamine release and this effect was absent in selective optogenetic stimulation [112]. Furthermore, Dai et al. [113] directly compared optogenetics and electrical stimulation in rhesus monkeys and demonstrated that both stimulation approaches produced a similar response in a lateral visuospatial discrimination task while stimulating the intraparietal area.

A portfolio of transgenic mouse lines has been quickly developed and made commercially available [114]. Optogenetic reporters are either inserted downstream of a variety of neuronal promoters, such as the pan-neuronal marker Thy1 [115], or cell-specificity is introduced by crossing Cre driver lines with lines containing optogenetic probes downstream of a floxed STOP cassette $[76,116]$. The resulting offspring have the STOP cassette deleted in the Creexpressing neurons, producing mice expressing cell-type specific ChR2. Recently, various intersectional targeting tools have been developed (Cre/Flp-dependent, Cre/Dre-dependent, and Cre/tTA-dependent) that allow highly selective targeting to multiple cells types with 2- to 4-fold higher expression than Cre-dependent only lines such as the Ai14 level in these mice $[117,118]$.

Optogenetics can be used to manipulate specific cell types and circuits by using either the Cre-inducible ChR2 transgenic mice or viral expression of $\mathrm{ChR} 2$, in combination with viral vectors expressing trans-synaptic tracers, such as the plant lectin wheat germ agglutinin (WGA), which provides retro-/ anterograde shuttling to postsynaptic target neurons. A variety of circuit targeting approaches can be used, as detailed in other reviews. As an example, we chose the cerebellar dentatethalamo-cortical circuit to illustrate different ways optogenetic 
strategies can be used (Fig. 2). Electrical stimulation of the dentate nucleus in rats has been shown to promote recovery and enhance plasticity [62-65]. Tracing studies using the rabies virus have indicated that different divisions of the dentate nucleus mediate different functions. While the dorsal dentate is more motor and premotor, the ventral dentate involves nonmotor functions such as motivation, cognition, and visual-spatial functions [119-121]. Studies have reported the presence of 3 major distinct cell types in the dentate nucleus: non- $\gamma$-aminobutyric acid (GABA)ergic (glutamatergic), small GABAergic, and small glycinergic [122, 123]. It is unclear which of these cell types and/or projections mediate the beneficial effect on stroke recovery. Optogenetic manipulations can be performed at the soma or terminal, as well as in combination with trans-synaptic tracers for projection targeting to dissect the involvement of various dentate circuits in stroke recovery (Fig. 2). One way to achieve cell-specific stimulation is to use viral vectors with promoters such as CamKII to drive expression of $\mathrm{ChR} 2$ in excitatory neurons (Fig. 2a). Injection of CamKII-ChR2 into the Th can express ChR2 in excitatory neurons. Subsequent stimulation in the Th will result in activation of connected areas such as the motor/premotor cortex (CTX). For well-defined neural circuits such as the thalamocortical connection between the Th and the CTX, a scenario similar to the previous one can be used with the exception of placing the optical fiber in projection terminal regions such as the CTX (Fig. 2b). For targeting unknown projections from deep nuclei such as the Th toward the cortex, a retrograde tracer such as WGA-Cre [109] and a Credependent ChR2 [with a loxP-flanked STOP cassette (LSL)] are injected into the CTX and Th, respectively (Fig. 2c). The projection is genetically labeled if WGA-Cre and LSL-ChR2 are present leading to Cre-dependent excision of the STOP codon and ChR2 expression. For multisynaptic neural circuits such as dentate-thalamo-cortical pathway, viral tracers from the rabies virus genetically engineered to cross multiple synapses are used [124] (Fig. 2d). In this example rabies virus-expressing $\mathrm{ChR} 2$ is injected into the dentate nucleus, which travels anterogradely through the Th toward the CTX. Optogenetic stimulation of cortical areas provides specific activation of $\mathrm{ChR} 2$ in the corresponding axonal terminals.

Independent of the experimental paradigm, successful optogenetics requires several controls and tests of stimulation parameters. For virus injections a control group should be included with a nonfunctional opsin expressed by the same virus. Cell toxicity and leaky expression are best identified by histology, electrical recordings, or molecular profiling. For selective stimulation of neural circuits, homogenous expression is necessary and the fiber optical device can be adapted to the anatomical structure and size. In general, the size of the light source, the fiber tip (which determines the focus or spread of light), and light intensity can be varied. With these parameters it is possible to calculate the heat produced by the light stimulation [125], and verify that tissue heating is limited to approximately $1{ }^{\circ} \mathrm{C}$ - the value below which neural and hemodynamic activity are affected [126, 127]. Thus, direct stimulations in the lesion area or peri-infarct area may have a negative effect on recovery. In our optogenetic studies, we target healthy areas that project to the lesion area, which demonstrated a beneficial effect on recovery [26]. Given the approximate laser power for stimulation, the frequency, duration, and intervals of stimulations should be determined empirically depending on the brain region and cell type of interest. For example, single action potentials in parvalbumin (PV) inhibitory neurons of the primary somatosensory cortex are achieved by brief $(<10 \mathrm{~ms})$, high powered $(>10 \mathrm{~mW})$ laser pulses $[128,129]$, whereas longer $(1 \mathrm{~s})$, low-power $(0.1-$ $3 \mathrm{~mW}$ ) laser pulses are sufficient to drive spiking in striatal neurons [130]. Depending on the type of opsin used, the stimulation frequency and interval should match the intrinsic photocycle for high stimulation efficiency and low opsin desensitization [76, 131]. Stimulation parameters can also be
Fig. 2 Optogenetic targeting of neural circuits in the mouse brain. The illustration depicts various targeting strategies, including (a) cell-body stimulation, (b) stimulation of an anatomically defined projection, (c) identification of a projection via retrograde terminal stimulation, and (d) targeting long-range, multisynaptic projections. ChR2 = channelrhodopsin; WGA $=$ wheat germ agglutinin; $\mathrm{CTX}=$ motor/premotor cortex; $\mathrm{Th}=$ thalamus; $\mathrm{LSL}=$ loxPflanked STOP cassette a Cell-body stimulation

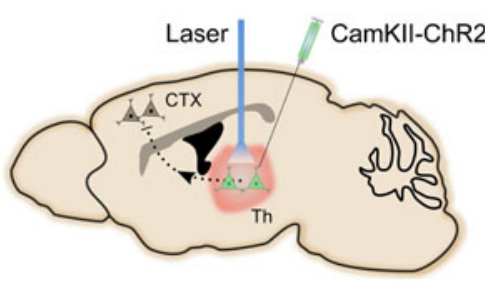

c Retrograde terminal stimulation $\mathbf{d}$

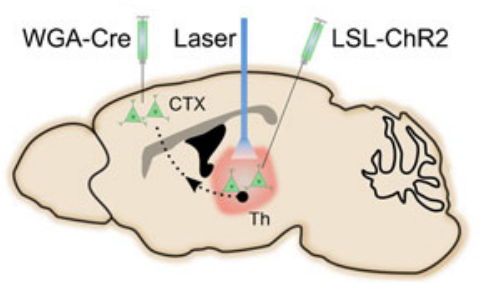

b Projection stimulation

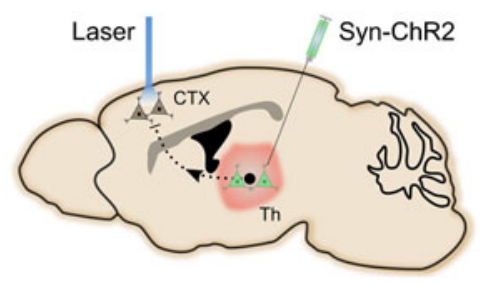

Long-range projection stimulation

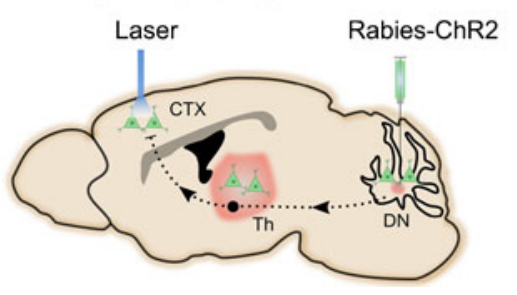


determined based on the types of neurons and their recorded spike trains. The effect of the stimulation paradigm can be monitored by either observing a simple behavioral response (e.g., limb movements or circling for primary motor areas) or simultaneous recordings of more precise or quantitative output, such as electrical recordings, calcium indicator-based activation, or laser Doppler flowmetry for assessing the stimulation-induced neurovascular coupling response (see "Multimodal Approaches Using Optogenetics and Other Techniques" below for more discussion on optogenetics and multimodal approaches).

\section{What We Can Learn from Using Optogenetics to Investigate Neural Circuits in Stroke Repair}

The Experimental Set-Up: Step-by-Step As discussed earlier, the exact role of contralesional M1 (cM1) activation is controversial [132]. Functional magnetic resonance imaging (fMRI) studies in humans suggest that, owing to disrupted interhemispheric inhibition, cM1 activity may be beneficial in the first 10 days after a stroke [25], yet correlates with a negative outcome if it persists [9]. With the optogenetic tools and calcium indicators described in the previous section, neural activity of excitatory cells with contralesional connections can be manipulated at different time points, and a direct readout of neural activity in the iM1 can be obtained using fiber photometry. Figure 3 illustrates an example of the experimental set-up to address this question. 1) Injection of the Creinducible ChR2 [AAV5.EF1.dflox.hChR2(H134R)mCherry.WPRE.hGH] in the cM1 (left) of CamKII $\alpha$-Cre transgenic mice [rB6.Cg-Tg(CamKIIa-cre)T29-1Stl/J; JAX005359], and injection of the calcium indicator GCaMP6 (AAV5.Syn.Flex.GCaMP6f.WPRE.SV40) in the iM1 (right). Cre recombinase will be expressed only in CamKII $\alpha$ excitatory cells, thus limiting the expression of $\mathrm{ChR} 2$ and GCaMP6 to these cells only in which Cre mediates deletion of the STOP codon upstream of the inserts. An optical fiber will be implanted in cM1 to allow light delivery, and another optical fiber will be implanted in iM1 for fiber photometry. 2) For optogenetic stimulation, a laser cable is tethered to the implant to transmit the blue light directly into the $\mathrm{cM} 1$. The same blue laser light is used to excite the GCaMP6. 3) At different time intervals during and after stimulation, the activity of iM1 is recorded as in vivo calcium-dependent changes in the GCaMP6 fluorescence. This powerful setting allows control over the excitatory neuronal activity in the $\mathrm{cM} 1$ and provides insights on how iM1 activity is influenced over the time course of stroke progression. An interesting alternative would be to couple the iM1 neural activity readout as feedback to modulate cM1 stimulation. Such closed-loop and activityguided control of neural circuit dynamics can be powerful while studying behaving mice [133].

\section{Optogenetic Studies in Various Disease Models}

Optogenetic manipulation of neuronal subtypes and neural circuits has proven to be particularly useful in investigating various neurological disorders. By inserting a step-function opsin for long-lasting neuronal hyperexcitability, Yamamoto et al. [134], in a mouse model of Alzheimer's disease, demonstrated that chronic optogenetic activation of the perforant path for up to 5 months increased $\beta$-amyloid burden in amyloid precursor protein mice in the hippocampal projection area by approximately 2.5 -fold compared with the contralateral side [134]. The side effects of chronic stimulations were epileptic seizures, which might have contributed to the $\beta$ amyloid pathology. Optogenetics has also been used to study temporal lobe epilepsy. In an animal model of pharmacologically induced seizures, optogenetic intervention of a subpopulation of GABAergic cells in the hippocampus or inhibition of excitatory principal cells (with projections outside the hippocampus) could stop the seizures. Krook-Magnuson et al. [80] used a closed-loop stimulation set-up in which laseractivated seizures were automatically detected with video and EEG recording in real-time. Furthermore, optogenetics has been widely used to study Parkinson's disease. Optogenetic inhibition of the subthalamic nucleus improved 6-hydroxydopamine-induced Parkinson symptoms such as forelimb akinesia [79]. Optogenetics is also useful for dissecting more complex neural circuits of behavior such as in the psychiatric diseases of depression, addiction, and autism [135]. In order to translate the exciting findings of rodent studies, optogenetic probes and set-ups need to be adapted and confirmed to induce specific behavior in primates. A first step are viral vectors with human promoters that efficiently drive expression of optogenetic probes [136], as well further development of implantable wireless light-emitting diode systems to replace optical fiber-based laser stimulation [137].

\section{Optogenetic Interrogation of Post-stroke Remapping and Recovery}

\section{Cortical Remapping Post-stroke}

Motor and sensory functions are governed by an intricate network of cortical and subcortical connections involving both excitatory and inhibitory circuits [138]. Brain injury such as stroke can disrupt this balance and cause changes in both the lesion area and remotely connected regions [22]. Wide-scale circuit-level remapping can occur early after stroke without formation of new structural connections; this can be partly due to the disinhibition that occurs after stroke [23, 139]. As described in previous sections, stroke can disrupt interhemispheric inhibition, which results in disinhibition and excessive transient activation in the contralesional cortex (see Fig. 1). 
1) Optogenetic targeting

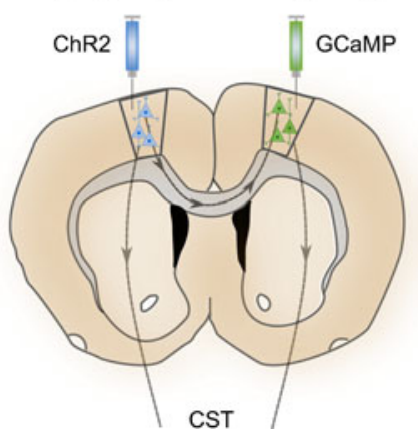

2)

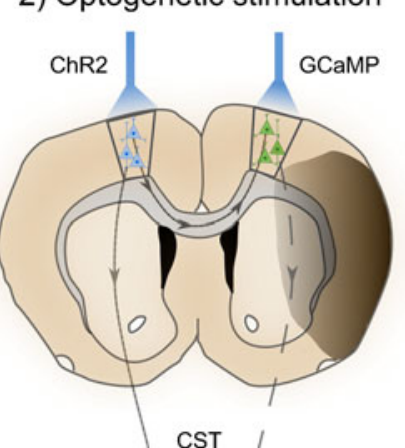

3) Optogenetic readout

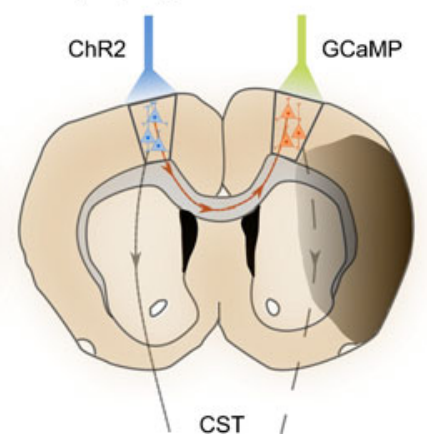

Fig. 3 Schematic of an all-optical experiment to investigate the crosstalk between activation of contralesional motor cortex (cM1) and the ipsilesional M1 (iM1) in proximity to the ischemic lesion (highlighted by a dark gray shadow). In a 3-step approach, 1) virus is injected to target expression of channelrhodopsin (ChR2) and GCaMP6 to homotopic motor brain areas, followed by 2) the laser-based stimulation of optogenetic

Structural and connectivity changes continue to occur for weeks after stroke $[10,11,13]$; thus, understanding the spatial and temporal progression of neural circuit dynamics and linking these altered circuits with new structural connections will be critical for developing therapeutic strategies to promote post-stroke recovery.

Studies in both humans and animals have demonstrated functional cortical remapping after stroke [5, 7, 48]. fMRI and positron emission tomography (PET) imaging in stroke patients have demonstrated activation of the contralesional hemisphere when moving the affected limb. Longitudinal imaging studies indicate that this contralesional activation is transient and gradually returns to baseline, especially in patients with good motor recovery $[9,25,140]$. However, the role of contralesional cortex activation is still unclear. Activation in the contralesional cortex at the early post-stroke phase (i.e., 10 days) has been associated with improved recovery $[25,141]$. Furthermore, disrupting the contralesional cortex activity using TMS also resulted in motor impairment [45]. These studies suggest that increasing contralesional cortex activation after stroke is beneficial. However, the interhemispheric inhibition model suggests that contralesional activation may be maladaptive, and this is supported by studies using repetitive TMS that demonstrated improved motor function after inhibition of contralesional cortex activation [40, 41, 47]. Thus, the role of the contralesional cortex remains controversial, and its role in stroke recovery may be dependent on time, location, and severity of stroke. Motor training studies have also highlighted the involvement of the dorsal premotor cortex in stroke recovery, as increased activity in this region was detected in stroke patients with improved motor performance [142], and disruption of the premotor area resulted in worsened motor performance. Most of the cortical remapping studies in humans rely on the use of limb movement, which involves mostly motor and sensory cortical activations. Future studies need to investigate brain-wide network changes, probes, and 3) detection of calcium-dependent changes in fluorescence emission due to activation of cells in iM1 via transcallosal projections from $\mathrm{cM} 1$. The potentially disrupted pyramidal projection from layer 5 neurons in the cortex through the cortical spinal tract (CST) into the contralateral spinal cord is indicated by a dashed line

including subcortical regions, that may contribute to poststroke recovery.

Animal studies have also revealed activity changes in periinfarct and remotely connected regions after stroke $[8,10,12$, $13,82]$. Imaging techniques, such as intrinsic optical imaging, VSD imaging, and 2-photo calcium imaging, have been used in conjunction with forelimb stimulations to study post-stroke activation patterns and functional remapping. Remapping occurs after stroke most prominently in peri-infarct zones, but is also observed in connected regions such as the unaffected hemisphere (e.g., contralesional cortex) [13, 82, 139, 143, 144]. Remodeling in peri-infarct zones and in the unaffected hemisphere, such as loss and recovery of dendritic spines and axonal sprouting, has been reported [12, 145, 146]. Prolonged activation in reorganized cortical areas in both peri-infarct and distant areas is correlated with increased structural plasticity $[11,13]$. In addition, stroke produces a loss of proper sensory motor maps, and sensory representations can remap onto nearby areas. At 1-2 months after stroke, surviving neurons that were originally highly limb selective can evolve into responding to multiple limbs $[22,144]$. This adaptive plasticity within neuronal networks contributes to cortical remapping and recovery after stroke [8, 22, 144].

In addition to remodeling in peri-infarct zones, animals that have a focal stroke in the motor or somatosensory cortex also exhibit activation changes in remotely connected areas, such as the unaffected hemisphere or subcortical regions [139]. Rapid changes in sensory processing in the peri-infarct area can occur within minutes of stroke. Using forelimb stimulations in a photothrombotic stroke model, Mohajerani et al. [139] revealed that these sensory-evoked changes can occur bilaterally, and in the unaffected contralesional hemisphere these activity changes are detected at $30 \mathrm{~min}$ after stroke. Interestingly, deactivation of thalamic activity by tetrodotoxin before stroke blocked the bilateral sensory activation. Furthermore, sensory-evoked activity in the unaffected hemisphere 
can occur in acallosal mice despite absence of transcallosal connections [139], further suggesting the importance of subcortical circuits in interhemispheric inhibition after stroke. How these rapid changes that occur after stroke evolve during the recovery phase remains to be elucidated. These rapid changes in sensory processing can also cause metabolic changes and potentially alter neurovascular coupling which can affect neuronal function and recovery.

Recently, Lim et al. [82, 147] used optogenetic approaches to interrogate post-stroke circuit reorganization and functional remapping. They mapped functional cortical connectivity with systematic ChR2 stimulation in conjunction with VSD imaging. VSD imaging and ChR2 stimulation revealed network-wide plasticity after stroke, and a strong parallel in cortical connectivity was seen between ChR2 stimulations and sensory stimulations [82]. However, the sensory stimulations produced weaker responses while the $\mathrm{ChR} 2$ stimulations produced stronger VSD responses, suggesting that optogenetic stimulation using ChR2 may be more useful for probing intracortical circuits. They observed a global depressed response at 1 week after stroke and this extended to the unaffected hemisphere. At 8 weeks after stroke, this depression had recovered significantly. At the local peri-infarct areas, ChR2 photostimulation of the peri-infarct zone revealed a heterogeneous recovery; some areas (anterior-lateral) remained depressed while others areas (posterior-medial) recovered by 8 weeks after stroke, indicating a nonuniform recovery of peri-infarct areas [82]. These findings are consistent with the notion that stroke affects a brain-wide network and further supports the involvement of noninjured remotely connected regions in stroke recovery $[22,24]$. Owing to the limitation of the VSD technique, this study did not investigate involvement of prefrontal circuits or subcortical circuits. Other groups have used resting state fMRI to investigate brainwide network changes after stroke, which allows a more global and longitudinal investigation [100, 148, 149]. Although this is promising, the resting state frequencies are low and the algorithms used to calculate the network dynamics still need to be optimized for proper interpretation of these data.

Optogenetic approaches have also been used to study cortical excitability within hours after stroke [150-152]. Anenberg et al. [150] used optogenetics to investigate cortical excitability and motor output in a ministroke model generated by occlusion of arterioles in the motor cortex. ChR2-evoked EEG, spinal, and electromyography responses revealed a mismatch of cortical excitability and motor output within $1 \mathrm{~h}$ of stroke [150], consistent with the observed depression of excitability after stroke, further supporting that cortical excitability is impaired early after stroke and this impairment can be observed in remotely connected regions. Furthermore, optogenetics has been used to interrogate the cell types involved in excitability and recovery [151]. Xie et al. [151] examined the plasticity of inhibitory circuits after a global ischemia stroke model that mimics cardiac arrest and heart attacks, as inhibitory interneurons are important in regulating excitability and plasticity after stroke. PV neurons are one of the more abundant inhibitory neuron subtypes, and studies have reported that PV neurons in the hippocampus are more resistant to global ischemia [153, 154]. Using optogenetics and Cre-dependent transgenic mice, Xie et al. [151] interrogated stimulation-evoked (optogenetic $v s$ forelimb) activation changes in the mouse somatosensory cortex after stroke with a multichannel optrode, and investigated PV-mediated GABAergic activity and its dendritic structural changes. Despite the recovery of dendritic structures in PV neurons, there was a suppression of PV GABAergic synaptic transmission after global ischemia [151], which could contribute to the imbalance of excitation and inhibition after stroke, and lead to motor and sensory deficits. Future studies can use optogenetic approaches to interrogate the involvement of inhibitory networks in stroke recovery, such as specifically targeting these PV-mediated inhibitory circuits. Other inhibitory cell types such as somatostatin (SOM)-inhibitory neurons may also be a promising target for stroke recovery, as these SOM-inhibitory neurons in the motor cortex have been recently demonstrated to be key regulators of synaptic plasticity changes in motor learning [155]. This work came from Komiyama's group, where they used optogenetic approaches to examine the involvement of GABAergic inhibitory circuits in synaptic plasticity changes during motor learning. They manipulated PV- or SOM-inhibitory neurons and found that motor learning induced subtype-specific plasticity of inhibitory circuits in the motor cortex. Interestingly, while SOMinhibitory neurons inhibit the distal apical dendrites of excitatory neurons, PV-inhibitory neurons inhibit somatic and perisomatic dendrites of the excitatory neurons [155]. It would be interesting to investigate whether optogenetic manipulation of SOM-inhibitory circuits can affect post-stroke recovery.

Besides the involvement of various inhibitory neuron subtypes in recovery, GABA receptor-mediated signaling has been demonstrated to play important roles in post-stroke recovery. Clarkson et al. [156] reported that increased tonic GABA signaling (through extrasynaptic GABA-A receptors) occurred in the peri-infarct cortex during stroke recovery, and reducing this tonic GABA-mediated inhibition promotes recovery. Interestingly, while tonic GABA signaling is increased after stroke, phasic GABA signaling mediated via synaptic GABA-A receptors is decreased after stroke. Recently our group demonstrated that enhancing phasic GABA signaling promotes post-stroke recovery, further highlighting the importance of phasic GABA signaling in recovery [157]. The GABA-B receptor may also play an important role in stroke recovery, as these receptors are thought to mediate interhemispheric inhibition [158]. Palmer et al. [158] used a combination of optogenetics and pharmacological tools to demonstrate that long-lasting interhemispheric inhibition acts via a specific 
cortical microcircuitry mediated by dendritic GABA-B receptors. Whether GABA-B receptor signaling is critical in stroke recovery remains to be elucidated. Future studies using a combination of optogenetics targeting specific circuits and specific pharmacological inhibitors will be very helpful in dissecting important inhibitory circuits in stroke recovery.

\section{Optogenetic Approaches to Target Neural Circuits in Post-stroke Recovery}

In the previous section, we highlighted studies that used forelimb stimulations or optogenetic stimulation to investigate cortical excitability and functional remapping after stroke. While these studies yielded important insights on activation patterns and circuit remapping after stroke, it is unclear whether some of these activated regions/circuits are beneficial or maladaptive for recovery. To interrogate circuits involved in stroke recovery, our group used optogenetics to manipulate directly specific cell types and neural circuits after stroke and investigate the effects on stroke recovery [26]. One of the first brain regions we focused on was the ipsilesional primary mortex cortex (iM1). Using transgenic mice expressing ChR2 under a Thy-1 promoter, after stroke we stimulated neurons in the iM1 specifically, which targets multiple circuits, including corticospinal, cortico-cortico, and corticothalamic. The ability to stimulate specific cell types with precise timing will likely have a greater therapeutic benefit and provide a clearer understanding of post-stroke recovery mechanisms. Our study reported the first evidence of enhanced recovery using optogenetic neuronal stimulation [26]. We demonstrated that repeated stimulation of neurons in the iM1 of freely behaving stroke mice was sufficient to activate multiple plasticity-associated mechanisms and improve functional recovery [26]. To create an ischemic infarct in the rodent brains, we inserted an intraluminal suture through the common carotid artery to occlude transiently the middle cerebral artery, thus producing a large infarct in the striatum and sensory cortex that resulted in sensory-motor deficits (Fig. 4). One of the major behavior tests we use to evaluate functional recovery is the rotating beam test - a measure of how fast and how far a mouse can run across a $120 \mathrm{~cm}$ beam that rotates slowly at $3 \mathrm{rpm}$. We demonstrated that stimulated stroke mice performed better on the rotating beam test in both distance and speed traveled by day 14 (Fig. 5). As a second measure of recovery, stimulated mice exhibited faster weight gain than nonstimulated stroke control mice [26].

Our data also indicated that repeated iM1 neuronal stimulations can restore the temporary depression of the ipsilesional neurovascular coupling response after stroke [26]. Consistent with the current concept of a global depression of blood flow and excitability in the early stage after stroke, we observed a decrease in $\mathrm{CBF}$ and neurovascular coupling response in stroke mice at post-stroke day 5 , in both ipsilesional and contralesional hemispheres. However, repeated iM1-stimulated mice exhibited a significant increase in $\mathrm{CBF}$ and neurovascular coupling response at post-stroke day 15 [26], consistent with the view that neuronal activity drives hemodynamic signals. Recent evidence has shown that optogenetic stimulation of cortical excitatory neurons increases blood oxygen level dependent (BOLD) signals $[127,159,160]$. Interestingly, we observed a sustained larger $\mathrm{CBF}$ increase after the laser was turned OFF [26], which has not been previously reported. This larger CBF increase suggests that iM1-stimulated mice maintained a functional neurovascular coupling system more similar to sham mice, as the nonstimulated stroke mice lacked this response.

One rationale behind neuronal stimulation is that increased neuronal activity enhances structural plasticity - such as axonal sprouting or dendritic branching [15, 161]. Our data suggest that stimulation may also promote functional recovery by enhancing structural plasticity. Repeated neuronal stimulations significantly increased the expression of activitydependent neurotrophins, including brain-derived neurotrophic factor, nerve growth factor, and neurotrophin 3 [26]. These trophic factors have been shown to enhance regrowth and remapping of neural circuits [17, 161, 162]. Indeed, we also detected a significant increase in GAP43 expression [26], a growth-associated protein critical for axonal sprouting. Interestingly, stimulating the iM1 increased the expression of these neurotrophins and GAP43 in the contralesional motor cortex (cM1), highlighting the involvement of the uninjured hemisphere in stroke recovery. Future studies will determine the role of the contralesional circuits involved in recovery, using specific circuit manipulations with various opsins and trans-synaptic tracers. For example, using specific projection targeting with CRE-inducible ChR2 and a WGA retrograde tracer, we can directly stimulate only the transcallosal projecting neurons that innervate the contralesional cortex and examine its effect on neurotrophin expression and stroke outcome.

\section{Multimodal Approaches Using Optogenetics and Other Techniques: Brain-wide Screening for Changes in Neural Circuits After Stroke}

Brain-wide screening for changes in the neural circuits involved in stroke recovery has benefited tremendously from recent technical developments in the optogenetic toolbox (see Fig. 3b). In addition, the technical devices used have been improved and modified to better adapt to the mouse brain. For example, wireless stimulation and readouts of head-restrained, freely moving mice is now possible for interrogation and monitoring of neural activity during motor behavior [137, 163]. Furthermore, light delivery options have been expanded into devices such as an optrode system for laser excitation and multielectrode recording [164, 165], and a multifunctional fiber system for simultaneous optical, electrical, and chemical 


\section{a ipsilesional contralesional}

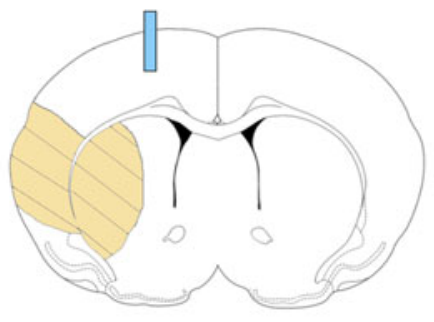

b Stimulation Paradigm

\begin{tabular}{|c|c|c|c|c|}
\hline $\begin{array}{l}1 \mathrm{~min} 1 \mathrm{~min} \\
\text { rest stim }\end{array}$ & $\begin{array}{c}3 \text { min } \\
\text { rest }\end{array}$ & $\begin{array}{l}1 \mathrm{~min} \\
\mathrm{stim}\end{array}$ & $\begin{array}{c}3 \mathrm{~min} \\
\text { rest }\end{array}$ & $\begin{array}{l}1 \mathrm{~min} 1 \mathrm{~min} \\
\text { stim rest }\end{array}$ \\
\hline
\end{tabular}

Fig. 4 Optogenetic stimulation paradigm and experimental design. (a) Diagram illustrates the optical fiber implant in the ipsilesional primary motor cortex (blue bar) and the infarct regions (orange). (b) Optogenetic stimulation paradigm. Each mouse received daily stimulations consisting of $3 \times 1$-min stimulations with a 3-min rest in between. (c) Experimental design for the optogenetic stimulation studies. Mice are trained on the

interrogation [166]. If a 2-photon microscopy set-up is used to record calcium signals, additional readouts important for stroke recovery are now possible, such as imaging of blood flow and synaptic structures [167].

However, optogenetic stimulation and readouts are restricted to specific brain regions and do not resolve global changes in network activity. Therefore, at present, optogenetics is particularly useful for mapping neural connections on a regional basis or between 2 structurally or functionally well-defined areas [147]. This gap could be narrowed by correlating optogenetic readouts with structural and functional in vivo data, for example by MRI of myelin fiber bundles via diffusion tensor imaging or diffusion spectrum imaging, and the hemodynamic response via BOLD fMRI [168]. These noninvasive techniques require only mild anesthesia or can be applied to awake rodents after or during the optogenetic stimulation paradigm [127]. However, these techniques are still
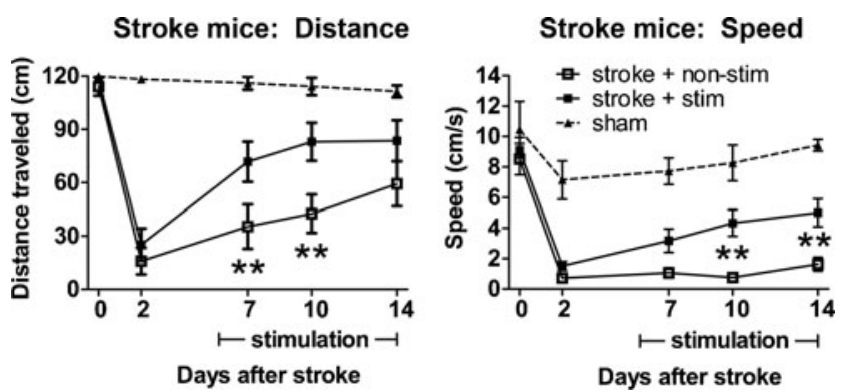

Fig. 5 Optogenetic neuronal stimulations improved functional recovery after stroke. Stimulated stroke mice performed significantly better in the rotating beam test, with a longer distance traveled and a faster speed. ${ }^{*} p<0.05,{ }^{* *} p<0.01$, significant difference between stimulated (stim) and nonstimulated (non-stim) group, 2-way repeated measures analysis of variance with Fisher's least significant difference. Sham: $n=8$; nonstim: $n=16$; stim: $n=21$. This figure is reproduced from our original study [26] rotating beam test prior to fiber implant. Training consists of 3 pretraining sessions, a preimplant baseline, and a prestroke baseline. Optogenetic stimulations began at post-stroke day 5 , and behavior tests are performed on post-stroke days 4,7,10, and 14. Mice are sacrificed for histology or western analysis. This figure is modified from our original study [26]. $\mathrm{CBF}=$ cerebral blood flow; $\mathrm{Sac}=$ sacrifice

being optimized to overcome limitations in the small mouse brain. Notably, Po et al. [169] successfully resolved the 3dimensional (3D) model of main fiber tract (diffusion fiber tracking based on diffusion spectrum imaging data) changes in rats and found reorganization of the ipsilesional internal capsule at 4 weeks after stroke. In addition, by combining fMRI in the same rats they reported a transhemispheric fiber connection through the corpus callosum that was lost in the rats without recovery of BOLD signals at 5 weeks after stroke. Van Meer et al. [143] applied serial diffusion tensor imaging and resting-state fMRI, in which no stimulus was applied but the spontaneous BOLD fluctuations were analyzed, in order to correlate white matter integrity and functional connectivity to stroke recovery. Similar to a scenario described in patients, improvement of sensorimotor function is correlated with restoration of interhemispheric functional connectivity and normalization of network configuration of the bilateral sensorimotor cortex.

Recently, fMRI has been successfully combined with optogenetic stimulation (opto-fMRI) and shows high potential to provide the missing link between the specific stimulation of brain circuits and the resulting activation of locally and remotely connected brain areas [127]. One of the first examples of axonal projection targeting in conjunction with functional imaging was described by Lee et al. [160] to allow circuitspecific mapping. Independent stimulation of transduced corticothalamic and thalamocortical axons between M1 and the Th demonstrated distinct patterns of activation. Interestingly, corticothalamic fiber activation produced unilateral activation of the Th and cortex, while thalamocortical stimulation produced bilateral activation. This demonstrates an important proof of concept for circuit-specific modulation.

One interesting aspect of brain-wide screening for neural circuits would be the ex vivo characterization of brain areas 
identified during an opto-fMRI experiment, where brain regions activated by optogenetics are detected during fMRI scanning. However, conventional histology/immunohistochemistry and subsequent fluorescence microscopy of thin slices (usually 10-30 $\mu \mathrm{m}$ ) highlights changes in cell structure and molecular composition, but does not provide the necessary 3D context, although $3 \mathrm{D}$ reconstruction from images of consecutive 2dimensional sections can be performed. Such ex vivo analyses could benefit from tissue-clearing protocols such as CLARITY, which is a method that removes lipids from the brain and renders the tissue transparent, while also preserving nucleic acids and proteins, without dislocation, using an acrylamide-based hydrogel [170, 171]. CLARITY allows greater optical and molecular access for immunolabeling, and this procedure can be performed in whole brain or thick slices $(3 \mathrm{~mm})$, which minimize reconstruction of images compared with traditional techniques. In combination with light sheet microscopy [172], an ex vivo high-resolution $3 \mathrm{D}$ model of the cellular components of stroke recovery can be assembled.

\section{Translational Potential of Optogenetics and Limitations}

Optogenetic techniques have been used widely to study disease mechanisms, particularly in preclinical neuropsychiatric and neurological disorders [26, 78-82]. The major advantage of the optogenetics technique is its specific cell type circuit manipulations with temporal precision, which is difficult to achieve with existing brain stimulation techniques, such as deep brain stimulation, TMS, and tDCS [76, 77]. Although optogenetics is invaluable for interrogation of neural circuits in normal and disease states, significant technical obstacles need to be overcome before it can be used for therapeutic applications in humans. Clinical use of optogenetics will require complementary advancement in other techniques such as gene therapy, opsin engineering, and opto-electronics/hardware development.

Efficient cell-specific targeting can be achieved with lentiviral or adenoviral viruses expressing the optogenetic probe tools under a cell-specific promoter [173]. Two excitatory (ChR2 and SFO) and 2 inhibitory (eNpHR 2.0 and ArchT) opsins have been successfully validated in primates [95, 136]. However, the long-term effects of ChR2 expression is a concern, as Miyashita et al. [174] recently demonstrated that high-level, long-term expression of ChR2-EYFP can induce abnormal axonal morphology and affect the organization of cortical circuits. Some opsin expressions can cause toxicity such as aggregation (please see detailed reviews [131, 175]). Another issue is that the viral genome is limited in size, especially in adenoassociated virus (AAV); thus, some of the larger promoters such as the inhibitory paralbumin promoter cannot be used in a viral vector. In addition, cross-species variation in opsin expression and function still needs to be optimized and tested with different promoters and vectors in humans. Both lentiviral and AAV have been used widely in optogenetic studies. These viral vectors are nonreplicating and well tolerated in rodents. AAV is a safer viral vector, as it is less likely to induce insertional mutagenesis and has a low immune response [176]. Thus, AAV2 has been commonly and safely used in a number of human clinical trials, including treatments for Parkinson's and Alzheimer's diseases [177, 178].

The success of optogenetics in humans will also depend on advances in light delivery and monitoring devices. Light is typically delivered through an optical fiber that is connected to a light source (laser or light-emitting diode). Significant light scattering occurs when the light is introduced into brain tissue. Only about $1 \%$ of the blue light power is delivered within $1 \mathrm{~mm}$ of its source [76]. Increasing light power can activate more opsins in a larger brain region; however, the heat from the light source can cause damage that may affect physiological and behavioral functions $[126,127]$. As the human brain is 10 times larger than the primate brain and 2500 times larger than the rodent brain, a major challenge of optogenetic use in humans will be activating sufficient opsins to drive a certain behavior without thermal damage. Thus, a low-heat light source and an opsin with a strong photocurrent or a more red-shifted activated opsin (infrared) will need to be developed.

The closed-loop recording and optogenetic stimulation system has been demonstrated to be useful in rodent models for studying seizures and epilepsy [80, 81]. Similar closed-loop optogenetic feedback systems designed for human monitoring would also be desirable. Recent developments in brain-machine interfaces have shown promising results, particularly for patients with amyotrophic lateral sclerosis, cervical spinal cord injury, and epilepsy. As part of the BrainGate2 pilot multisite clinical trial, Gilja et al. [179] have demonstrated the translational use of a neural prosthetic system in 2 patients with amyotrophic lateral sclerosis, with the highest performance ever reported. The clinical NeuroPace technology, another promising closed-loop sensing and stimulation system, has been recently approved for treating patients with medically intractable epilepsy [180, 181]. Furthermore, other braincomputer interface systems based on electrocorticography and intracortical microelectrode arrays have also demonstrated positive results in human studies for help restoring motor function in neurological/neurodegenerative diseases [182]. Future developments of incorporating optogenetics in these brain-machine interface devices would be invaluable for specific real-time circuit modulations. In addition, developments in pharmacogenetics, such as designer receptors exclusively activated by designer drugs, can provide a complementary approach to optogenetics for dissecting neural circuit mechanisms [183-185]. Designer receptors exclusively activated by designer drugs can be expressed in neurons, and specific 
neural circuits can be modulated using a synthetic small molecule such as clozapine-N-oxide $[185,186]$.

Despite the major hurdles mentioned above, optogenetics is an invaluable tool for understanding neural circuit remodeling during post-stroke recovery. Although optogenetics is not yet at the translational clinical stage, the cell type and circuit specificity offered by optogenetics can potentially result in greater efficacy and/or reduced side effects. Optogenetic "treatments or stimulation paradigms" that were successfully demonstrated in animal models will provide insightful information for the development of novel deep brain stimulation protocols in clinical settings. Furthermore, optogenetic-specific manipulation studies in conjunction with next-generation sequencing can reveal the transcriptome profile of stimulated stroke animals that exhibit behavioral improvement, which will help identify potential novel therapeutic pharmacological targets for stroke recovery.

Acknowledgments We thank Cindy H. Samos for assistance with this manuscript.

Required Author Forms Disclosure forms provided by the authors are available with the online version of this article.

\section{Compliance with Ethical Standards}

Funding This work was supported, in part, by National Institutes of Health National Institute of Neurological Disorders and Stroke grants R21NS82894 and R01NS093057 (to GKS); funding from Bernard and Ronni Lacroute, the William Randolph Hearst Foundation, and Russell and Elizabeth Siegelman (to GKS); and a postdoctoral fellowship from the Max Kade Foundation (to MA).

Conflict of Interest Dr. Steinberg serves on the Medtronic Neuroscience Strategic Advisory Board and is a consultant for Qool Therapeutics.

\section{References}

1. Davis SM, Donnan GA. 4.5 hours: The new time window for tissue plasminogen activator in stroke. Stroke 2009;40:22662267.

2. Lansberg MG, Bluhmki E, Thijs VN. Efficacy and safety of tissue plasminogen activator 3 to 4.5 hours after acute ischemic stroke: a metaanalysis. Stroke 2009;40:2438-2441.

3. George PM, Steinberg GK. Novel stroke therapeutics: unraveling stroke pathophysiology and its impact on clinical treatments. Neuron 2015;87:297-309.

4. Grotta JC, Hacke W. Stroke neurologist's perspective on the new endovascular trials. Stroke 2015;46:1447-1452.

5. Sharma N, Cohen LG. Recovery of motor function after stroke. Dev Psychobiol 2010;54:254-262.

6. Ward NS. Mechanisms underlying recovery of motor function after stroke. Postgrad Med J 2005;81:510-514.

7. Calautti C, Baron J-C. Functional neuroimaging studies of motor recovery after stroke in adults: a review. Stroke 2003;34:15531566.

8. Murphy TH, Corbett D. Plasticity during stroke recovery: from synapse to behaviour. Nat Rev Neurosci 2009;10:861-872.
9. Ward NS, Brown MM, Thompson AJ, Frackowiak RSJ. Neural correlates of motor recovery after stroke: a longitudinal fMRI study. Brain 2003;126:2476-2496.

10. Carmichael ST. Cellular and molecular mechanisms of neural repair after stroke: making waves. Ann Neurol 2006;59:735-742.

11. Clarkson AN, López-Valdés HE, Overman JJ, Charles AC, Brennan KC, Thomas Carmichael S. Multimodal examination of structural and functional remapping in the mouse photothrombotic stroke model. J Cereb Blood Flow Metab 2013;33:716-723.

12. Brown CE, Li P, Boyd JD, Delaney KR, Murphy TH. Extensive turnover of dendritic spines and vascular remodeling in cortical tissues recovering from stroke. J Neurosci 2007;27:4101-4109.

13. Brown CE, Aminoltejari K, Erb H, Winship IR, Murphy TH. In vivo voltage-sensitive dye imaging in adult mice reveals that somatosensory maps lost to stroke are replaced over weeks by new structural and functional circuits with prolonged modes of activation within both the peri-infarct zone and distant sites. J Neurosci 2009;29:1719-1734.

14. Carmichael ST. Plasticity of cortical projections after stroke. Neuroscientist 2003;9:64-75.

15. Carmichael ST, Chesselet M-F. Synchronous neuronal activity is a signal for axonal sprouting after cortical lesions in the adult. $\mathrm{J}$ Neurosci 2002;22:6062-6070.

16. Markus A, Patel TD, Snider WD. Neurotrophic factors and axonal growth. Curr Opin Neurobiol 2002;12:523-531.

17. Mattson MP. Glutamate and neurotrophic factors in neuronal plasticity and disease. Ann N Y Acad Sci 2008;1144:97-112.

18. Zhu JM, Zhao YY, Chen SD, Zhang WH, Lou L, Jin X. Functional recovery after transplantation of neural stem cells modified by brain-derived neurotrophic factor in rats with cerebral ischaemia. J Int Med Res 2011;39:488-498.

19. Li S, Overman JJ, Katsman D, et al. An age-related sprouting transcriptome provides molecular control of axonal sprouting after stroke. Nat Neurosci 2010;13:1496-1504.

20. Overman JJ, Clarkson AN, Wanner IB, et al. A role for ephrin-A5 in axonal sprouting, recovery, and activity-dependent plasticity after stroke. Proc Natl Acad Sci U S A 2012;109:E2230-E2239.

21. Li S, Nie EH, Yin Y, et al. GDF10 is a signal for axonal sprouting and functional recovery after stroke. Nat Neurosci 2015;18:17371745.

22. Silasi G, Murphy TH. Stroke and the connectome: how connectivity guides therapeutic intervention. Neuron 2014;83:13541368.

23. Xerri C, Zennou-Azogui Y, Sadlaoud K, Sauvajon D. Interplay between intra- and interhemispheric remodeling of neural networks as a substrate of functional recovery after stroke: adaptive versus maladaptive reorganization. Neuroscience 2014;283:178201.

24. Grefkes C, Fink GR. Reorganization of cerebral networks after stroke: New insights from neuroimaging with connectivity approaches. Brain 2011;134:1264-1276.

25. Rehme AK, Fink GR, Von Cramon DY, Grefkes C. The role of the contralesional motor cortex for motor recovery in the early days after stroke assessed with longitudinal fMRI. Cereb Cortex 2011:21:756-768

26. Cheng MY, Wang EH, Woodson WJ, et al. Optogenetic neuronal stimulation promotes functional recovery after stroke. Proc Natl Acad Sci 2014;111:1213-1218.

27. Rossi C, Sallustio F, Di Legge S, Stanzione P, Koch G. Transcranial direct current stimulation of the affected hemisphere does not accelerate recovery of acute stroke patients. Eur J Neurol 2013;20:202-204.

28. Johnston DG, Denizet M, Mostany R, Portera-Cailliau C. Chronic in vivo imaging shows no evidence of dendritic plasticity or functional remapping in the contralesional cortex after stroke. Cereb Cortex 2013;23:751-762. 
29. Meyer JS, Obara K, Muramatsu K. Diaschisis. Neurol Res 1993;15:362-366.

30. Sobesky J, Thiel A, Ghaemi M, et al. Crossed cerebellar diaschisis in acute human stroke: a PET study of serial changes and response to supratentorial reperfusion. J Cereb Blood Flow Metab 2005;25: 1685-1691.

31. Lin DDM, Kleinman JT, Wityk RJ, et al. Crossed cerebellar diaschisis in acute stroke detected by dynamic susceptibility contrast MR perfusion imaging. Am J Neuroradiol 2009;30:710-715.

32. Gauthier L V, Taub E, Perkins C, Ortmann M, Mark VW, Uswatte G. Remodeling the brain: plastic structural brain changes produced by different motor therapies after stroke. Stroke 2008;39: $1520-1525$.

33. Taub E, Uswatte G, Elbert T. New treatments in neurorehabilitation founded on basic research. Nat Rev Neurosci 2002;3:228-236.

34. Taub E, Morris DM. Constraint-induced movement therapy to enhance recovery after stroke. Curr Atheroscler Rep 2001;3:279286.

35. Andres RH, Horie N, Slikker W, et al. Human neural stem cells enhance structural plasticity and axonal transport in the ischaemic brain. Brain. 2011;134:1777-89.

36. Horie N, Pereira MP, Niizuma K, et al. Transplanted stem cellsecreted vascular endothelial growth factor effects poststroke recovery, inflammation, and vascular repair. Stem Cells 2011;29: 274-285.

37. Brown J a, Lutsep HL, Weinand M, Cramer SC. Motor cortex stimulation for the enhancement of recovery from stroke: a prospective, multicenter safety study. Neurosurgery 2006;58:464473.

38. Plow EB, Carey JR, Nudo RJ, Pascual-Leone A. Invasive cortical stimulation to promote recovery of function after stroke: a critical appraisal. Stroke 2009;40:1926-1931.

39. Teskey GC, Flynn C, Goertzen CD, Monfils MH, Young NA. Cortical stimulation improves skilled forelimb use following a focal ischemic infarct in the rat. Neurol Res 2003;25:794-800.

40. Grefkes C, Nowak DA, Wang LE, Dafotakis M, Eickhoff SB, Fink GR. Modulating cortical connectivity in stroke patients by rTMS assessed with fMRI and dynamic causal modeling. Neuroimage 2010;50:233-242.

41. Takeuchi N, Chuma T, Matsuo Y, Watanabe I, Ikoma K. Repetitive transcranial magnetic stimulation of contralesional primary motor cortex improves hand function after stroke. Stroke 2005;36:2681-2686.

42. Lindenberg R, Renga V, Zhu LL, Nair D, Schlaug G. Bihemispheric brain stimulation facilitates motor recovery in chronic stroke patients. Neurology 2010;75:2176-2184.

43. Bashir S, Mizrahi I, Weaver K, Fregni F, Pascual-Leone A. Assessment and modulation of neural plasticity in rehabilitation with transcranial magnetic stimulation. PM R 2010;2:S253-S268.

44. Chollet F, Dipiero V, Wise RJS, Brooks DJ, Dolan RJ, Frackowiak RSJ. The functional anatomy of motor recovery after stroke in humans: A study with positron emission tomography. Ann. Neurol 1991;29:63-71.

45. Lotze M, Markert J, Sauseng P, Hoppe J, Plewnia C, Gerloff C. The role of multiple contralesional motor areas for complex hand movements after internal capsular lesion. J Neurosci 2006;26: 6096-6102.

46. Cramer SC, Nelles G, Benson RR, et al. A functional MRI study of subjects recovered from hemiparetic stroke. Stroke 1997;28: 2518-2527.

47. Nowak DA, Grefkes C, Dafotakis M, et al. Effects of lowfrequency repetitive transcranial magnetic stimulation of the contralesional primary motor cortex on movement kinematics and neural activity in subcortical stroke. Arch Neurol 2008;65: $741-747$
48. Grefkes C, Ward NS. Cortical reorganization after stroke: how much and how functional? Neuroscientist 2014;20:56-70.

49. Nowak DA, Grefkes C, Ameli M, Fink GR. Interhemispheric competition after stroke: brain stimulation to enhance recovery of function of the affected hand. Neurorehabil Neural Repair 2009;23:641-656.

50. Takeuchi N, Izumi S-I. Maladaptive plasticity for motor recovery after stroke: mechanisms and approaches. Neural Plast 2012;2012: 359728.

51. Bütefisch CM, Wessling M, Netz J, Seitz RJ, Hömberg V. Relationship between interhemispheric inhibition and motor cortex excitability in subacute stroke patients. Neurorehabil Neural Repair 2008;22:4-21.

52. Kleim J a, Bruneau R, VandenBerg P, MacDonald E, Mulrooney $\mathrm{R}$, Pocock D. Motor cortex stimulation enhances motor recovery and reduces peri-infarct dysfunction following ischemic insult. Neurol Res 2003;25:789-793.

53. Zheng J, Liu L, Xue X, et al. Cortical electrical stimulation promotes neuronal plasticity in the peri-ischemic cortex and contralesional anterior horn of cervical spinal cord in a rat model of focal cerebral ischemia. Brain Res 2013;1504:25-34.

54. Adkins-Muir DL, Jones TA. Cortical electrical stimulation combined with rehabilitative training: enhanced functional recovery and dendritic plasticity following focal cortical ischemia in rats. Neurol Res 2003;25:780-788.

55. Adkins DL, Hsu JE, Jones TA. Motor cortical stimulation promotes synaptic plasticity and behavioral improvements following sensorimotor cortex lesions. Exp Neurol 2008;212:14-28.

56. Boychuk JA, Adkins DL, Kleim JA. Distributed versus focal cortical stimulation to enhance motor function and motor map plasticity in a rodent model of ischemia. Neurorehabil Neural Repair 2011;25:88-97.

57. Huang M, Harvey RL, Stoykov ME, et al. Cortical stimulation for upper limb recovery following ischemic stroke: a small phase II pilot study of a fully implanted stimulator. Top Stroke Rehabil 15: 160-172.

58. Brown JA, Lutsep H, Cramer SC, Weinand M. Motor cortex stimulation for enhancement of recovery after stroke: case report. Neurol Res 2003;25:815-818.

59. Phillips NI, Bhakta BB. Affect of deep brain stimulation on limb paresis after stroke. Lancet 2000;356:222-223.

60. Nandi D, Smith H, Owen S, Joint C, Stein J, Aziz T. Periventricular grey stimulation versus motor cortex stimulation for post stroke neuropathic pain. J Clin Neurosci 2002;9: 557-561.

61. Papuć E, Obszańska K, Trojanowski T, Szczepańska-Szerej H, Rejdak K, Stelmasiak Z. Reduction of thalamic tremor with deep brain stimulation performed for post stroke chronic central pain. Ann Agric Environ Med 2013;1:45-47.

62. Baker KB, Schuster D, Cooperrider J, Machado AG. Deep brain stimulation of the lateral cerebellar nucleus produces frequencyspecific alterations in motor evoked potentials in the rat in vivo. Exp Neurol 2010;226:259-264.

63. Machado A, Baker KB. Upside down crossed cerebellar diaschisis: proposing chronic stimulation of the dentatothalamocortical pathway for post-stroke motor recovery. Front Integr Neurosci 2012;6:20.

64. Machado AG, Baker KB, Schuster D, Butler RS, Rezai A. Chronic electrical stimulation of the contralesional lateral cerebellar nucleus enhances recovery of motor function after cerebral ischemia in rats. Brain Res 2009;1280:107-116.

65. Cooperrider J, Furmaga H, Plow E, et al. Chronic deep cerebellar stimulation promotes long-term potentiation, microstructural plasticity, and reorganization of perilesional cortical representation in a rodent model. J Neurosci 2014;34:9040-9050. 
66. Feng WW, Bowden MG, Kautz S. Review of transcranial direct current stimulation in poststroke recovery. Top Stroke Rehabil 2013;20:68-77.

67. Cortes M, Black-Schaffer RM, Edwards DJ. Transcranial magnetic stimulation as an investigative tool for motor dysfunction and recovery in stroke: an overview for neurorehabilitation clinicians. Neuromodulation 2012;15:316-325.

68. Werhahn KJ, Conforto AB, Kadom N, Hallett M, Cohen LG. Contribution of the ipsilateral motor cortex to recovery after chronic stroke. Ann Neurol 2003;54:464-472.

69. Wessel MJ, Zimerman M, Hummel FC. Non-invasive brain stimulation: an interventional tool for enhancing behavioral training after stroke. Front Hum Neurosci 2015;9:265.

70. Liew S-L, Santarnecchi E, Buch ER, Cohen LG. Non-invasive brain stimulation in neurorehabilitation: local and distant effects for motor recovery. Front Hum Neurosci 2014;8:378.

71. Takatsuru Y, Fukumoto D, Yoshitomo M, Nemoto T, Tsukada H, Nabekura J. Neuronal circuit remodeling in the contralateral cortical hemisphere during functional recovery from cerebral infarction. J Neurosci 2009;29:10081-10086.

72. Takatsuru Y, Eto K, Kaneko R, et al. Critical role of the astrocyte for functional remodeling in contralateral hemisphere of somatosensory cortex after stroke. J Neurosci 2013;33:4683-4692.

73. Pham L-DD, Hayakawa K, Seo JH, et al. Crosstalk between oligodendrocytes and cerebral endothelium contributes to vascular remodeling after white matter injury. Glia 2012;60:875-881.

74. Iwai M, Stetler RA, Xing J, et al. Enhanced oligodendrogenesis and recovery of neurological function by erythropoietin after neonatal hypoxic/ischemic brain injury. Stroke 2010;41:1032-1037.

75. Zhao Y, Rempe DA. Targeting astrocytes for stroke therapy. Neurotherapeutics 2010;7:439-451

76. Yizhar O, Fenno LE, Davidson TJ, Mogri M, Deisseroth K. Optogenetics in neural systems. Neuron 2011;71:9-34.

77. Fenno L, Yizhar O, Deisseroth K. The development and application of optogenetics. Annu Rev Neurosci 2011;34:389-412.

78. Gradinaru V, Mogri M, Thompson KR, Henderson JM, Deisseroth K. Optical deconstruction of parkinsonian neural circuitry. Science 2009;324:354-359.

79. Yoon HH, Park JH, Kim YH, et al. Optogenetic inactivation of the subthalamic nucleus improves forelimb akinesia in a rat model of parkinson disease. Neurosurgery 2014;74:533-540.

80. Krook-Magnuson E, Armstrong C, Oijala M, Soltesz I. Ondemand optogenetic control of spontaneous seizures in temporal lobe epilepsy. Nat Commun 2013;4:1376.

81. Paz JT, Davidson TJ, Frechette ES, et al. Closed-loop optogenetic control of thalamus as a tool for interrupting seizures after cortical injury. Nat Neurosci 2013;16:64-70.

82. Lim DH, LeDue JM, Mohajerani MH, Murphy TH. Optogenetic mapping after stroke reveals network-wide scaling of functional connections and heterogeneous recovery of the peri-infarct. J Neurosci 2014;34:16455-16466.

83. Boyden ES, Zhang F, Bamberg E, Nagel G, Deisseroth K. Millisecond-timescale, genetically targeted optical control of neural activity. Nat Neurosci 2005;8:1263-1268.

84. Nagel G, Szellas T, Huhn W, et al. Channelrhodopsin-2, a directly light-gated cation-selective membrane channel. Proc Natl Acad Sci U S A 2003;100:13940-13945.

85. Lanyi JK, Oesterhelt D. Identification of the retinal-binding protein in halorhodopsin. J Biol Chem 1982;257:2674-2677.

86. Zhang F, Wang L-P, Brauner M, et al. Multimodal fast optical interrogation of neural circuitry. Nature 2007;446:633-639.

87. McIsaac RS, Bedbrook CN, Arnold FH. Recent advances in engineering microbial rhodopsins for optogenetics. Curr Opin Struct Biol 2015;33:8-15.
88. Zhang F, Wang L-P, Boyden ES, Deisseroth K. Channelrhodopsin-2 and optical control of excitable cells. Nat Methods 2006;3:785-792.

89. Gunaydin LA, Yizhar O, Berndt A, Sohal VS, Deisseroth K, Hegemann P. Ultrafast optogenetic control. Nat Neurosci 2010;13:387-392.

90. Lin JY, Knutsen PM, Muller A, Kleinfeld D, Tsien RY. ReaChR: a red-shifted variant of channelrhodopsin enables deep transcranial optogenetic excitation. Nat Neurosci 2013;16:1499-1508.

91. Zhang F, Prigge M, Beyrière F, et al. Red-shifted optogenetic excitation: a tool for fast neural control derived from Volvox carteri. Nat Neurosci 2008;11:631-633.

92. Klapoetke NC, Murata Y, Kim SS, et al. Independent optical excitation of distinct neural populations. Nat Methods 2014;11:338346.

93. Chuong AS, Miri ML, Busskamp V, et al. Noninvasive optical inhibition with a red-shifted microbial rhodopsin. Nat Neurosci 2014;17:1123-1129.

94. Berndt A, Lee SY, Ramakrishnan C, Deisseroth K. Structureguided transformation of channelrhodopsin into a light-activated chloride channel. Science 2014;344:420-424.

95. Han X, Chow BY, Zhou H, et al. A high-light sensitivity optical neural silencer: development and application to optogenetic control of non-human primate cortex. Front Syst Neurosci 2011;5:18.

96. Berndt A, Yizhar O, Gunaydin LA, Hegemann P, Deisseroth K. Bi-stable neural state switches. Nat Neurosci 2009;12:229-234.

97. Yizhar O, Fenno LE, Prigge M, et al. Neocortical excitation/ inhibition balance in information processing and social dysfunction. Nature 2011;477:171-178.

98. Kim JM, Hwa J, Garriga P, Reeves PJ, RajBhandary UL, Khorana HG. Light-driven activation of beta2-adrenergic receptor signaling by a chimeric rhodopsin containing the beta2-adrenergic receptor cytoplasmic loops. Biochemistry 2005;44:2284-2292.

99. Airan RD, Thompson KR, Fenno LE, Bernstein H, Deisseroth K. Temporally precise in vivo control of intracellular signalling. Nature 2009;458:1025-1029.

100. Bauer AQ, Kraft AW, Wright PW, Snyder AZ, Lee JM, Culver JP Optical imaging of disrupted functional connectivity following ischemic stroke in mice. Neuroimage 2014;99:388-401.

101. Buzsáki G, Anastassiou CA, Koch C. The origin of extracellular fields and currents-EEG, ECoG, LFP and spikes. Nat Rev Neurosci 2012 407-420

102. Grinvald A, Hildesheim R. VSDI: a new era in functional imaging of cortical dynamics. Nat Rev Neurosci 2004;5:874-885.

103. Knöpfel T. Genetically encoded optical indicators for the analysis of neuronal circuits. Nat Rev Neurosci 2012;13:687-700.

104. Akerboom J, Carreras Calderón N, Tian L, et al. Genetically encoded calcium indicators for multi-color neural activity imaging and combination with optogenetics. Front Mol Neurosci 2013;6:2.

105. Akemann W, Mutoh H, Perron A, Rossier J, Knöpfel T. Imaging brain electric signals with genetically targeted voltage-sensitive fluorescent proteins. Nat Methods 2010;7:643-649.

106. Grewe BF, Langer D, Kasper H, Kampa BM, Helmchen F. Highspeed in vivo calcium imaging reveals neuronal network activity with near-millisecond precision. Nat Methods 2010;7:399-405.

107. Keller GB, Bonhoeffer T, Hübener M. Sensorimotor mismatch signals in primary visual cortex of the behaving mouse. Neuron 2012;74:809-815.

108. Mukamel EA, Nimmerjahn A, Schnitzer MJ. Automated analysis of cellular signals from large-scale calcium imaging data. Neuron 2009;63:747-760.

109. Gunaydin L a., Grosenick L, Finkelstein JC, et al. Natural neural projection dynamics underlying social behavior. Cell 2014;157: $1535-1551$ 
110. Hochbaum DR, Zhao Y, Farhi SL, et al. All-optical electrophysiology in mammalian neurons using engineered microbial rhodopsins. Nat Methods 2014;11:825-833.

111. Packer AM, Russell LE, Dalgleish HWP, Häusser M. Simultaneous all-optical manipulation and recording of neural circuit activity with cellular resolution in vivo. Nat Methods 2015;12:140-146.

112. Melchior JR, Ferris MJ, Stuber GD, Riddle DR, Jones SR. Optogenetic versus electrical stimulation of dopamine terminals in the nucleus accumbens reveals local modulation of presynaptic release. J Neurochem 2015;134:833-844.

113. Dai J, Brooks DI, Sheinberg DL. Optogenetic and electrical microstimulation systematically bias visuospatial choice in primates. Curr Biol 2014;24:63-69.

114. Asrican B, Augustine GJ, Berglund K, et al. Next-generation transgenic mice for optogenetic analysis of neural circuits. Front Neural Circuits 2013;7:160.

115. Fenno LE, Gunaydin LA, Deisseroth K. Mapping anatomy to behavior in Thy1:18 ChR2-YFP transgenic mice using optogenetics. Cold Spring Harb Protoc 2015;2015: pdb.prot075598.

116. Madisen L, Mao T, Koch H, et al. A toolbox of Cre-dependent optogenetic transgenic mice for light-induced activation and silencing. Nat Neurosci 2012;15:793-802.

117. Madisen L, Garner AR, Shimaoka D, et al. Transgenic mice for intersectional targeting of neural sensors and effectors with high specificity and performance. Neuron 2015;85:942-958.

118. Fenno LE, Mattis J, Ramakrishnan C, et al. Targeting cells with single vectors using multiple-feature Boolean logic. Nat Methods 2014;11:763-772

119. Dum RP, Li C, Strick PL. Motor and nonmotor domains in the monkey dentate. Ann N Y Acad Sci 2002;978:289-301.

120. Dum RP, Strick PL. An unfolded map of the cerebellar dentate nucleus and its projections to the cerebral cortex. J Neurophysiol 2003;89:634-639.

121. Küper M, Dimitrova A, Thürling M, et al. Evidence for a motor and a non-motor domain in the human dentate nucleus - an fMRI study. Neuroimage 2011;54:2612-2622.

122. Bäurle J, Grüsser-Cornehls U. Differential number of glycine- and GABA-immunopositive neurons and terminals in the deep cerebellar nuclei of normal and Purkinje cell degeneration mutant mice. J Comp Neurol 1997;382:443-458.

123. Uusisaari M, Knöpfel T. GlyT2+ neurons in the lateral cerebellar nucleus. Cerebellum 2010;9:42-55.

124. Nguyen TD, Wirblich C, Aizenman E, Schnell MJ, Strick PL, Kandler K. Targeted single-neuron infection with rabies virus for transneuronal multisynaptic tracing. J Neurosci Methods 2012;209:367-370

125. Stujenske JM, Spellman T, Gordon JA. Modeling the spatiotemporal dynamics of light and heat propagation for in vivo optogenetics. Cell Rep 2015;12:525-534.

126. Christie IN, Wells JA, Southern P, et al. fMRI response to blue light delivery in the naïve brain: implications for combined optogenetic fMRI studies. Neuroimage 2013;66:634-641.

127. Desai M, Kahn I, Knoblich U, et al. Mapping brain networks in awake mice using combined optical neural control and fMRI. J Neurophysiol 2011;105:1393-1405.

128. Cardin JA, Carlén M, Meletis K, et al. Targeted optogenetic stimulation and recording of neurons in vivo using cell-type-specific expression of Channelrhodopsin-2. Nat Protoc 2010;5:247-254.

129. Lima SQ, Hromádka T, Znamenskiy P, Zador AM. PINP: a new method of tagging neuronal populations for identification during in vivo electrophysiological recording. PLoS One 2009;4:e6099.

130. Royer S, Zemelman B V, Barbic M, Losonczy A, Buzsáki G, Magee JC. Multi-array silicon probes with integrated optical fibers: light-assisted perturbation and recording of local neural circuits in the behaving animal. Eur J Neurosci 2010;31:22792291

131. Lin JY. A user's guide to channelrhodopsin variants: features, limitations and future developments. Exp Physiol 2011;96:19-25.

132. Wahl A, Schwab ME. Finding an optimal rehabilitation paradigm after stroke: enhancing fiber growth and training of the brain at the right moment. Front Hum Neurosci 2014;8:381.

133. Grosenick L, Marshel JH, Deisseroth K. Closed-loop and activityguided optogenetic control. Neuron 2015;86:106-139.

134. Yamamoto K, Tanei Z, Hashimoto T, et al. Chronic optogenetic activation augments $A \beta$ pathology in a mouse model of alzheimer disease. Cell Rep 2015;11:859-865.

135. Tye KM, Deisseroth K. Optogenetic investigation of neural circuits underlying brain disease in animal models. Nat Rev Neurosci 2012;13:251-266.

136. Diester I, Kaufman MT, Mogri M, et al. An optogenetic toolbox designed for primates. Nat Neurosci 2011;14:387-397.

137. Rossi MA, Go V, Murphy T, Fu Q, Morizio J, Yin HH. A wirelessly controlled implantable LED system for deep brain optogenetic stimulation. Front Integr Neurosci 2015;9:8

138. Lodato S, Rouaux C, Quast KB, et al. Excitatory projection neuron subtypes control the distribution of local inhibitory interneurons in the cerebral cortex. Neuron 2011;69:763-779.

139. Mohajerani MH, Aminoltejari K, Murphy TH. Targeted ministrokes produce changes in interhemispheric sensory signal processing that are indicative of disinhibition within minutes. Proc Natl Acad Sci U S A 2011;108:E183-E191.

140. Tombari D, Loubinoux I, Pariente J, et al. A longitudinal fMRI study: in recovering and then in clinically stable sub-cortical stroke patients. Neuroimage 2004;23:827-839.

141. Zimerman M, Heise KF, Hoppe J, Cohen LG, Gerloff C, Hummel FC. Modulation of training by single-session transcranial direct current stimulation to the intact motor cortex enhances motor skill acquisition of the paretic hand. Stroke 2012;43:2185-2191.

142. Johansen-Berg H, Dawes H, Guy C, Smith SM, Wade DT, Matthews PM. Correlation between motor improvements and altered fMRI activity after rehabilitative therapy. Brain 2002;125: 2731-2742.

143. Van Meer MP a., Otte WM, van der Marel K, et al. Extent of bilateral neuronal network reorganization and functional recovery in relation to stroke severity. J Neurosci 2012;32:4495-4507.

144. Winship IR, Murphy TH. Remapping the somatosensory cortex after stroke: insight from imaging the synapse to network. Neuroscientist 2009;15:507-524.

145. Li P, Murphy TH. Two-photon imaging during prolonged middle cerebral artery occlusion in mice reveals recovery of dendritic structure after reperfusion. J Neurosci 2008;28: 11970-11979.

146. Zhang S, Boyd J, Delaney K, Murphy TH. Rapid reversible changes in dendritic spine structure in vivo gated by the degree of ischemia. J Neurosci 2005;25:5333-5338.

147. Lim DH, Ledue J, Mohajerani MH, Vanni MP, Murphy TH. Optogenetic approaches for functional mouse brain mapping. Front Neurosci 2013;7:54.

148. Wu J, Quinlan EB, Dodakian L, et al. Connectivity measures are robust biomarkers of cortical function and plasticity after stroke. Brain 2015;138:2359-2369.

149. Van Meer MPA, van der Marel K, Otte WM, Berkelbach van der Sprenkel JW, Dijkhuizen RM. Correspondence between altered functional and structural connectivity in the contralesional sensorimotor cortex after unilateral stroke in rats: a combined restingstate functional MRI and manganese-enhanced MRI study. J Cereb Blood Flow Metab 2010;30:1707-1711.

150. Anenberg E, Arstikaitis P, Niitsu Y, et al. Ministrokes in channelrhodopsin-2 transgenic mice reveal widespread deficits 
in motor output despite maintenance of cortical neuronal excitability. J Neurosci 2014;34:1094-1104.

151. Xie Y, Chen S, Wu Y, Murphy TH. Prolonged deficits in parvalbumin neuron stimulation-evoked network activity despite recovery of dendritic structure and excitability in the somatosensory cortex following global ischemia in mice. J Neurosci 2014;34:14890-14900.

152. Chen S, Mohajerani MH, Xie Y, Murphy TH. Optogenetic analysis of neuronal excitability during global ischemia reveals selective deficits in sensory processing following reperfusion in mouse cortex. J Neurosci 2012;32:13510-13519.

153. Nitsch C, Scotti A, Sommacal A, Kalt G. GABAergic hippocampal neurons resistant to ischemia-induced neuronal death contain the Ca2(+)-binding protein parvalbumin. Neurosci Lett 1989;105: 263-268.

154. Freund TF, Buzsáki G, Leon A, Baimbridge KG, Somogyi P. Relationship of neuronal vulnerability and calcium binding protein immunoreactivity in ischemia. Exp Brain Res 1990;83:55-66.

155. Chen SX, Kim AN, Peters AJ, Komiyama T. Subtype-specific plasticity of inhibitory circuits in motor cortex during motor learning. Nat Neurosci 2015;18:1109-1115.

156. Clarkson AN, Huang BS, Macisaac SE, Mody I, Carmichael ST. Reducing excessive GABA-mediated tonic inhibition promotes functional recovery after stroke. Nature 2010;468:305-309.

157. Hiu T, Farzampour Z, Paz J, et al. Enhanced phasic GABA inhibition during the repair phase of stroke: a novel therapeutic target. Brain 2015. doi:10.1093/brain/awv360.

158. Palmer LM, Schulz JM, Murphy SC, Ledergerber D, Murayama $\mathrm{M}$, Larkum ME. The cellular basis of GABA(B)-mediated interhemispheric inhibition. Science 2012;335:989-993.

159. Urban A, Rancillac A, Martinez L, Rossier J. Deciphering the neuronal circuitry controlling local blood flow in the cerebral cortex with optogenetics in PV::Cre transgenic mice. Front Pharmacol 2012;3:105.

160. Lee JH, Durand R, Gradinaru V, et al. Global and local fMRI signals driven by neurons defined optogenetically by type and wiring. Nature 2010;465:788-792.

161. Schinder AF, Poo M. The neurotrophin hypothesis for synaptic plasticity. Trends Neurosci 2000;23:639-645.

162. Schäbitz W-R, Steigleder T, Cooper-Kuhn CM, et al. Intravenous brain-derived neurotrophic factor enhances poststroke sensorimotor recovery and stimulates neurogenesis. Stroke 2007;38:21652172.

163. Hamel EJO, Grewe BF, Parker JG, Schnitzer MJ. Review cellular level brain imaging in behaving mammals: An engineering approach. Neuron. 2015;86:140-159.

164. Zhang J, Laiwalla F, Kim JA, et al. Integrated device for optical stimulation and spatiotemporal electrical recording of neural activity in light-sensitized brain tissue. J Neural Eng 2009;6:055007.

165. Voigts J, Siegle JH, Pritchett DL, Moore CI. The flexDrive: an ultra-light implant for optical control and highly parallel chronic recording of neuronal ensembles in freely moving mice. Front Syst Neurosci 2013;7:8

166. Canales A, Jia X, Froriep UP, et al. Multifunctional fibers for simultaneous optical, electrical and chemical interrogation of neural circuits in vivo. Nat Biotechnol 2015;33:277-284.

167. Sigler A, Murphy TH. In vivo 2-photon imaging of fine structure in the rodent brain: before, during, and after stroke. Stroke 2010;41:S117-S123.
168. Hoehn M, Aswendt M. Structure-function relationship of cerebral networks in experimental neuroscience: contribution of magnetic resonance imaging. Exp Neurol 2013;242:65-73.

169. Po C, Kalthoff D, Kim YB, Nelles M, Hoehn M. White matter reorganization and functional response after focal cerebral ischemia in the rat. PLoS One 2012;7:e45629.

170. Tomer R, Ye L, Hsueh B, Deisseroth K. Advanced CLARITY for rapid and high-resolution imaging of intact tissues. Nat Protoc 2014;9:1682-1697.

171. Chung K, Wallace J, Kim S-Y, et al. Structural and molecular interrogation of intact biological systems. Nature 2013;497:332337.

172. Chung K, Deisseroth K. CLARITY for mapping the nervous system. Nat Methods 2013;10:508-513.

173. Zhang F, Gradinaru V, Adamantidis AR, et al. Optogenetic interrogation of neural circuits: technology for probing mammalian brain structures. Nat Protoc 2010;5:439-456.

174. Miyashita T, Shao YR, Chung J, Pourzia O, Feldman DE. Longterm channelrhodopsin-2 (ChR2) expression can induce abnormal axonal morphology and targeting in cerebral cortex. Front Neural Circuits 2013;7:8.

175. Allen BD, Singer AC, Boyden ES. Principles of designing interpretable optogenetic behavior experiments. Learn Mem 2015;22: 232-238.

176. Henckaerts E, Dutheil N, Zeltner N, et al. Site-specific integration of adeno-associated virus involves partial duplication of the target locus. Proc Natl Acad Sci U S A 2009;106:7571-7576.

177. Kaplitt MG, Feigin A, Tang C, et al. Safety and tolerability of gene therapy with an adeno-associated virus (AAV) borne GAD gene for Parkinson's disease: an open label, phase I trial. Lancet 2007;369:2097-2105.

178. Kaplitt MG. Gene therapy clinical trials in the human brain. Protocol development and review of current applications. Front Neurol Neurosci 2009;25:180-188.

179. Gilja V, Pandarinath $\mathrm{C}$, Blabe $\mathrm{CH}$, et al. Clinical translation of a high-performance neural prosthesis. Nat Med 2015;21:1142-1145.

180. Sun FT, Morrell MJ. The RNS System: responsive cortical stimulation for the treatment of refractory partial epilepsy. Expert Rev Med Devices 2014;11:563-572.

181. Lee B, Zubair MN, Marquez YD, et al. A single-center experience with the NeuroPace RNS system: A review of techniques and potential problems. World Neurosurg 2015;84:719-726.

182. Hiremath S V, Chen W, Wang W, et al. Brain computer interface learning for systems based on electrocorticography and intracortical microelectrode arrays. Front Integr Neurosci 2015;9: 40.

183. Vardy E, Robinson JE, Li C, et al. A new DREADD facilitates the multiplexed chemogenetic interrogation of behavior. Neuron 2015;20:936-946.

184. Aston-Jones G, Deisseroth K. Recent advances in optogenetics and pharmacogenetics. Brain Res 2013;1511:1-5.

185. Armbruster BN, Li X, Pausch MH, Herlitze S, Roth BL. Evolving the lock to fit the key to create a family of $G$ protein-coupled receptors potently activated by an inert ligand. Proc Natl Acad Sci U S A 2007; 104:5163-5168.

186. Vazey EM, Aston-Jones G. New tricks for old dogmas: optogenetic and designer receptor insights for Parkinson's disease. Brain Res 2013;1511:153-163. 